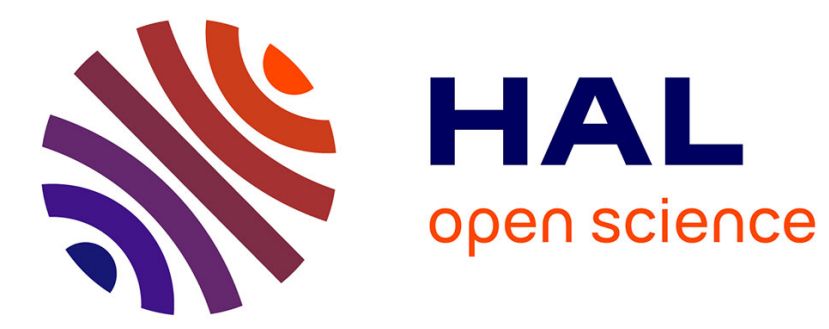

\title{
Factors contributing to CT scan usability
}

Saad Aldoihi, Omar Hammami

\section{To cite this version:}

Saad Aldoihi, Omar Hammami. Factors contributing to CT scan usability. IEEE International Conference on Computational Intelligence and Virtual Environments for Measurement Systems and Applications (CIVEMSA), Jun 2020, Tunis (virtuel ), Tunisia. 10.1109/CIVEMSA48639.2020.9132747. hal-03047351

\section{HAL Id: hal-03047351 \\ https://hal.science/hal-03047351}

Submitted on 16 Dec 2020

HAL is a multi-disciplinary open access archive for the deposit and dissemination of scientific research documents, whether they are published or not. The documents may come from teaching and research institutions in France or abroad, or from public or private research centers.
L'archive ouverte pluridisciplinaire HAL, est destinée au dépôt et à la diffusion de documents scientifiques de niveau recherche, publiés ou non, émanant des établissements d'enseignement et de recherche français ou étrangers, des laboratoires publics ou privés. 


\section{Factors contributing to CT scan usability}

\author{
Saad Aldoihi \\ Computer Science and Systems Engineering \\ ENSTA, Institut Polytechnique de Paris \\ Palaiseau Cedex, France \\ aldoihi@ensta.fr
}

\author{
Omar Hammami \\ Computer Science and Systems Engineering \\ ENSTA, Institut Polytechnique de Paris \\ Palaiseau Cedex, France \\ Hammami@ensta.fr
}

\begin{abstract}
Usability is essential to every functioning system, especially when the system is intertwined with people's safety and needs. Radiological diagnosis is a critical tool to identify diseases and tumors. Therefore, its usefulness is beyond question, despite its radiation risk. Many operational difficulties related to computed tomography (CT) scanning come in the form of nontechnical requirements. Hence, there is a need to examine the technical requirements that suit its context of use. This paper examines the barriers and enablers of CT scan usability within its operational context of use. In total, 11 CT scan technicians and one radiology doctor were interviewed to constitute the primary data of this paper. The study reveals that system engineering is critical to improving the current condition. The results show cases wherein the CT scan table jammed due to the weight of the patient.
\end{abstract}

Index Terms-Usability, CT scan Usability, CT scan usability factors.

\section{INTRODUCTION}

When evaluating many of today's machines and devices, their usefulness is decidedly determined by their usability. Capitalizing on merely technology execution is myopic. Rather, it must be accompanied by an effective and flourishing user experience. This notion ought to satisfy the execution of tasks with efficiency and effectiveness. Usability is not a monolithic concept. This expression is evidently demonstrated by the definition of usability. [1] found that a variety of usability definitions produced 152 attributes. Nonetheless, usability is vitally important in healthcare because it can offer unparalleled benefits, such as minimized medical errors and utilized times and speeds. Meanwhile, [2] found that current medical devices are profoundly vulnerable to serious human error due to lack of usability, and [3] postulated that in general, usability in healthcare is ambiguously structured and lacks quality. The primary reason for this is that usability in healthcare overemphasizes safety [4]. Determining the usability of a system is dependent on the parameters the system intended is to serve. Consequently, verifying and identifying the context of use is vitally critical for system acceptance and smoothness.

The context of use is determined by the internal and external environment in which the system is used. [5] stated that context of use is utterly significant; even when writing a postcard, the writer typically begins by describing the weather or the outside atmosphere. Principally, the context of use refers to the specific conditions under which the system would be used. These conditions can be straightforwardly expressed by attributes. For instance, a fast-food kiosk describes the general attributes of the user, which are hungry, determined by speed, and specifically chosen from among many lines of product. In other words, it is counterintuitive to measure the success of a system separate from its context of use.

Often, usability is measured by its flexibility to stretch and cover the maximum context of use. This paper will contribute to an overall understanding of usability within the context of use. It observes the usability of the computed tomography (CT) scan system from the lens of requirement engineering. This paper study the CT scan's system in use within Saudi Arabian hospitals. The paper is structured as follows. Section 2 discusses the role of technology to minimize current obstacles and barriers. Section 3 details the methodological approach. Section 4 illustrates the results. Finally, section 5 presents the discussion and conclusion.

\section{Role of TeChNOLOGY}

Since the introduction of technology, people have perceived it as an enabler attribute. In healthcare, the primary use of technology is to minimize risk and capitalize on safety [6]. Hospitals are using technology to record and store data from the daily operation process with the purpose of optimizing the user and patient experiences [7]. Conceptually, hospitals use technology for their critical core operations. Working in the healthcare environment renders a person enormously receptive to physical and mental extortions, and it is extremely governed by industry requirements and guidelines. Consequently, technology plays an important role in minimizing risks and preventing errors [8]. The foremost beneficial attributes of technology are as follows:

- Increased productivity

- Increased patient intake

- Increased comfort

- Maximized job accuracy

- Minimized time and costs

Requirement engineering is responsible for capturing context of use requirements. However, context of use varies based on environments and fits of purpose. Eventually, there will be a gap between the context of use and the captured requirement, and the primary role of requirement engineering is to reduce the gap, as shown in Figure 1. 


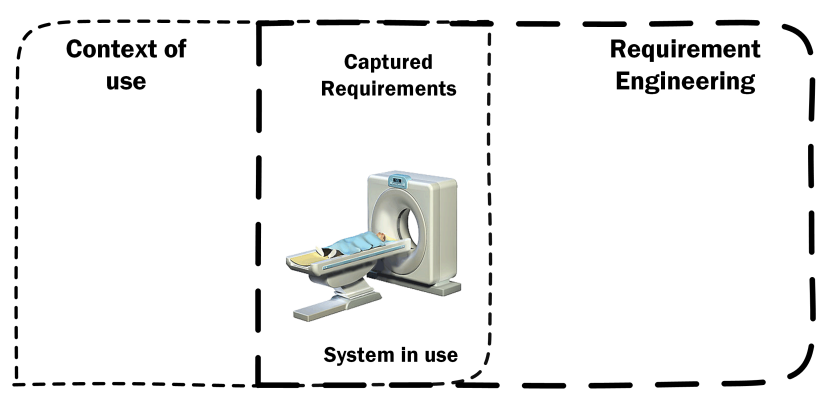

Fig. 1: Captured Requirement Engineering

\section{METHOD}

\section{A. Subjects}

All CT scan technicians and radiologists whose daily functions to operate the device are invited to participate in this study. In qualitative sampling, large sampling is excessively deemed unnecessary [9]. The purpose of the qualitative approach is to investigate a phenomenon in-depth and in length. Hence, Qualitative research usually takes excessive time and very a few samplings [10]. Consequently, the target population is considerably less than that in the Quantitive method.

The participants consist of $11 \mathrm{CT}$ scan technicians and one radiology doctor. They came from hospitals across Saudi Arabia. There were 11 male and two female participants. The participants belong to four age groups. Three participants range from 20 to 29 years old, fives from 30 to 39 years old, three from 40 to 49 years old, and one is over 50 years old. See Table 1 for demographic details.

TABLE I: Demographic Characteristic

\begin{tabular}{|l|c|c|c|c|}
\hline ID & Gender & Age & $\begin{array}{l}\text { Educational } \\
\text { level }\end{array}$ & $\begin{array}{l}\text { Radiology } \\
\text { Years } \\
\text { Experience }\end{array}$ \\
\hline Participant 1 & Male & $20-29$ & Bachelor & $0-3$ years \\
\hline Participant 2 & Male & $30-39$ & Bachelor & $12+$ years \\
\hline Participant 3 & Male & $20-29$ & Bachelor & $0-3$ years \\
\hline Participant 4 & Male & $30-39$ & Bachelor & $12+$ years \\
\hline Participant 5 & Male & $30-39$ & Master & $4-7$ years \\
\hline Participant 6 & Male & $30-39$ & diploma & $12+$ years \\
\hline Participant 7 & Male & $50+$ & Diploma & $12+$ years \\
\hline Participant 8 & Male & $20-29$ & Bachelor & $0-3$ years \\
\hline Participant 9 & Male & $30-39$ & Bachelor & $12+$ years \\
\hline Participant 10 & Female & $40-49$ & Master & $8-11$ years \\
\hline Participant 11 & Male & $40-49$ & Bachelor & $12+$ years \\
\hline Participant 12 & Female & $40-49$ & Bachelor & 8 - 11 years \\
\hline
\end{tabular}

\section{B. Reliability and Validity}

The concept of reliability and validity is a critical factor for the success of the research. Thus, Reliability and validity must be applied to the research to ensure that data and findings are evocative. In this study, internal review, feedback, and recommendation were received by the second author of this research and Radiologist consultant to ensure the feasibility and practicability of the questionnaire items. In terms of reliability, the questionnaire was dispersed to five CT scan technicians. Therefore, the participants demonstrated a respectable and good understanding of the questions.

\section{Data Collection and Analysis}

A qualitative approach was used to collect the data for this study. Interviews were utilized to achieve the objective of the study. After conducting the interviews, they were transcribed and translated to constitute the first step of qualitative content analysis. The translations were verified by a certified translator and by the second author who is well acquainted with the Arabic language. Then, the data were analyzed using the qualitative data analysis software Nvivo 12. After identifying and classifying the theme, it was given to the second author and external reviewer for feedbacks and reviews. . Saudi Arabia's CT scan market is dominated by three brands. These brand names have been blinded into brand $\mathrm{A}$, brand $\mathrm{B}$, and brand $\mathrm{C}$. Therefore, any referral to brand functionalities or features will be indicated as brand $\mathrm{A}$, brand $\mathrm{B}$, and brand $\mathrm{C}$.

\section{RESULTS}

All participants agree that usability is tremendously crucial to CT scanning. It benefits patients and hospitals alike. Hospital benefits include reduced appointments, increased productivity, and greater optimization of time and cost, while patient benefits include increased safety, reduced radiation, and increased comfort.

"When the device is easy to use, we can finish examining the patient in a short time. The patient does not feel anxious or afraid during the examination." Participant 7

"Usability affects the speed of scanning and saves time.” Participant 8

The thematic analysis of the content produces 22 usability attributes (see Table 2). The most referenced attributes are Information communicativeness (14 references) and Context of use (13 references). One major reference theme was the technician's ability to control the table from the control room. Some brands still lack this system functionality.

\section{A. Information communicativeness}

Information communicativeness comprises the information received from the system, such as icons, system alerts, sound alerts, and language communication. These communications can tremendously ease operation of the system.

"I think that icons should have detailed instructions so we are able to know what it does before clicking it. This will improve the usability of the device to a great extent. This is because even people with little 
TABLE II: Produced Attributes

\begin{tabular}{|c|c|c|}
\hline Attributes & $\begin{array}{l}\text { Number } \\
\text { of coding } \\
\text { references }\end{array}$ & $\begin{array}{l}\text { Number of } \\
\text { sources }\end{array}$ \\
\hline Context of use & 13 & 7 \\
\hline Easiness & 1 & 1 \\
\hline Effectiveness & 4 & 4 \\
\hline Efficiency & 3 & 2 \\
\hline Efficient to use & 1 & 1 \\
\hline Error prevention & 2 & 2 \\
\hline Functionally correct & 2 & 1 \\
\hline Helpfulness & 2 & 2 \\
\hline Image Quality & 4 & 3 \\
\hline $\begin{array}{l}\text { Information } \\
\text { communicativeness }\end{array}$ & 14 & 5 \\
\hline Learnability & 5 & 3 \\
\hline Operability & 4 & 3 \\
\hline Productivity & 4 & 3 \\
\hline Safety & 3 & 3 \\
\hline Speed of performance & 4 & 4 \\
\hline Standardization & 6 & 3 \\
\hline System functions & 8 & 3 \\
\hline System performance & 2 & 2 \\
\hline Training & 7 & 3 \\
\hline Useableness & 2 & 1 \\
\hline Usefulness & 6 & 4 \\
\hline User satisfaction & 1 & 1 \\
\hline
\end{tabular}

information will be able to use the device in such a case. When using the device for the first time, I faced a problem like this, and I was obligated to call another employee to help me understand what these icons meant..." Participant 1

Another crucial factor related to information communicativeness is audial commands, which direct the patient to take, hold, and release breath during the exam. This attribute is vital to both the technicians and the patients. The CT scan system has audial commands for the patient (for chest examination).

The device has more than 15 languages: Hindi, Bengali, Turkish, and Russian. I have nearly more than 15 languages on the system. I choose a suitable language for the patient and the device speaks it. Participant 7

"One time, we had a patient who only spoke Hindi, and we had to do a chest exam. Hindi exists on the device, but we had to activate it for the first time that day. Participant 8

"I know these devices have the ability to give audial instructions in English and Arabic. This is what I know and have experienced. The audial instructions directed to the patients by the device are in the Arabic and English languages. The Brand A device allows me to insert my personal audial instructions. On the contrary, the Brand $C$ device does not have this option as you choose the language of audial instructions, and it takes over the rest of the task. The Brand A device allows me to my personal audial instructions by recording my own voice; I can illustrate the instruction or summarize it as I want. On the contrary, the Brand C device doesn't allow this, as it speaks to the patient according to how it is programmed." Participant 10

Despite the technological development to include many languages, some patients found their languages were left out.

"There was a Somali patient; he did not speak Arabic or French and his father accompanied him. His father spoke English. During the exam, the patient had to take a breath, suppress the breath, and release the breath in precise time. The problem is that he did not speak English or Arabic, so we found ourselves obligated to make his father, who can speak English, wear lead protection and enter the scanning room with him. We were speaking in the speaker from the control room and his father translated sentences, including 'take a breath, suppress the breath, and release the breath." "Participant 3

\section{B. Context of use}

It compromises many activities that affect the operational process, such as movement during the exam and overweight patients. The primary concern in this category is overweight patient, as many CT scan tables jam due to patient weight.

"Unfortunately, movement during the exam can definitely ruin the quality of the image. We have repeated cases like these, especially when dealing with children. Because of their repeated movement, you may be obligated to retake the image once again." Participant 7

"I found myself obligated to tell the patient that he/she is overweight and as a result, the table will not move." Participant 2

"We have trouble with overweight patients, as mainly the table does not move quickly." Participant 1 


\section{Image quality}

It can be affected by many attributes. As stated above, movement is a major contributing factor, but movement is categorized within the context of use, as technicians need to deal with it as an operational context. When conducting an exam, it is observed that contrast dye leaks and eventually it affects the quality of the image.

"Sometimes a small proportion of the dye seeps inside the device. Eventually, this may affect image quality, as the device in such a case may produce incorrect images. Consequently, the technician may need to retake images more than once." Participant 9

"Regardless of the image quality, we have a general policy to avoid retaking images as much as possible." Participant 2

"There is no doubt that it is crucial that we rely on Axiology, as it has an important effect; if the image is clear, we can diagnose the case and if the image isn't clear, we can't diagnose the case.... If we are able to conclude a diagnosis, this will help the patient, as if we are able to conclude a diagnosis, the doctor will be able to as well. We can help the patient any way, but if things aren't clear and we can't conduct a diagnosis, then the scan can be considered useless and in such a case the patient is most affected by this." Participant 5

"The system gives audial instructions for the patients, like take a breath, suppress the breath, and release the breath. In the case of 'take a breath,' the device takes about a minute before taking an image so the lunge may fill with air. Some patients cannot suppress a breath for more than a minute, as originally, he/she is a patient. As a result, when the device takes the image, it takes the image when the breath is being released. This is the cause of taking an incorrect image. The point is that the orders from the system take a long time before taking the image. This affects the image greatly, as we re-examine the patient many times. This accordingly raises the radical dose for the patient." Participant 3

\section{DISCUSSION AND CONCLUSION}

Requirement engineering is utterly critical to enhanced usability and the user experience. As evidently shown in this study, when users cannot utilize the final product to suit the context of use, they tend to modify the product in accordance with their context of use requirement. As observed in one case, the radiology department installed a camera in the exam room because when the patient performs the exam, the patient became invisible from the control room. Therefore, improving patient visibility is crucial for safety reasons.
One extremely vital theme of this study is the audial command. It directs patients to follow an important exam protocol. Unfortunately, there are cases where the patient neither knows the local language (Arabic) nor other languages that already exist within the system. Audial commands can tremendously affect the safety of the patients and their immediate family members. In one particular case, a father was obligated to stay in the room to translate the audial orders for his ill son as a result of the unavailability of the language the patient speaks. Consequently, CT scanner manufacturers need to pay special attention to extremely diverse markets, such as the Gulf Cooperation Council (GCC) countries.

In essence, system engineering plays an important role in the context of use. The need to model a system in which the operational context of use is collected, stored, and analyzed is essential. The author's future work aim is to model an engineering system for capturing operational data for the purpose of implementing a more intelligent business model so certain activities can be improved.

\section{REFERENCES}

[1] Dubey, S. K., and Rana, A. (2010). Analytical roadmap to usability definitions and decompositions. International Journal of Engineering Science and Technology, 2(9), 4723-4729.

[2] Fairbanks, R. J., and Caplan, S. (2004). Poor interface design and lack of usability testing facilitate medical error. The Joint Commission Journal on Quality and Safety, 30(10), 579-584.

[3] Peute, L. W., Spithoven, R., and WM, P. J. B. M. (2008). Usability studies on interactive health information systems; where do we stand? In EHealth Beyond the Horizon: Get IT There: Proceedings of MIE2008, the XXIst International Congress of the European Federation for Medical Informatics (p. 327). IOS Press.

[4] Aldoihi, S., and Hammami, O. (2018, October). User experience of CT scan: A reflection of usability and exertions. In 2018 IEEE/ACS 15th International Conference on Computer Systems and Applications (AICCSA) (pp. 1-6). IEEE.

[5] Maguire, M. (2001). Context of use within usability activities. International Journal of Human-Computer Studies, 55(4), 453-483.

[6] Peute, L. W., Driest, K. F., Marcilly, R., Da Costa, S. B., Beuscart-Zephir, M. C., and Jaspers, M. W. (2013, September). A framework for reporting on human factor/usability studies of health information technologies. In CSHI (pp. 54-60).

[7] Côrtes, P. L., and Côrtes, E. G. D. P. (2011). Hospital information systems: a study of electronic patient records. JISTEM-Journal of Information Systems and Technology Management, 8(1), 131-154.

[8] Aldoihi, S., and Hammami, O. (2020). Usability evaluation and assessment of computed tomography scan. Intelligent Information Management, 12, 27-35. doi: 10.4236/iim.2020.121002.

[9] Holloway, I., and Galvin, K. (2016). Qualitative research in nursing and healthcare. John Wiley and Sons.

[10] Mir, R., and Jain, S. (Eds.). (2017). The Routledge Companion to Qualitative Research in Organization Studies. Routledge. 